\title{
Best Management Practices in the Everglades Agricultural Area: Fertilizer Spill Prevention ${ }^{1}$
}

\author{
O.A. Diaz, S.H. Daroub, R.W. Rice, T. A. Lang, and M. Chen ${ }^{2}$
}

\section{Introduction}

Plant nutrients such as phosphorus $(\mathrm{P})$ are applied to crops to optimize productivity and maximize profitability. However, excessive plant nutrient applications and improper application methods may result in nutrients moving into ground and surface waters. In addition, during the process of fertilizer application to agricultural fields, there is the potential for accidental fertilizer spills that can further negatively impact the quality of ground and surface waters.

Phosphorus fertilizer spill prevention is a Best Management Practice (BMP) approved by the South Florida Water Management District (SFWMD), one designed to reduce drainage $\mathrm{P}$ loads in the Everglades Agricultural Area (EAA). Spill prevention of $P$ fertilizers is a BMP that is widely implemented by growers in the EAA. This BMP is easily implemented and can have an immediate impact on reducing off-farm $\mathrm{P}$ loads. This EDIS document is part of a series of publications that provide current implementation guidelines for commonly employed farm-level BMPs designed to reduce P loads from farms located within the EAA basin.

\section{Fertilizer Spill Prevention}

Phosphorus is an essential element for plant growth, and since agricultural soils are often low in plant-available $\mathrm{P}$, supplementary applications of $\mathrm{P}$ are often necessary in order to maintain profitable crop production. However, $\mathrm{P}$ is also considered to be one of the main controlling factors underlying primary production (i.e., growth of photosynthetic organisms like algae, plants, etc.) in aquatic ecosystems. In cases where $\mathrm{P}$ fertilizer misuse leads to increases $\mathrm{P}$ levels within aquatic ecosystems, excessive algae and plant growth can occur, which contributes to eutrophication (environmental degradation) processes within fresh water lakes, streams, and wetlands. Many of the P fertilizer sources used in agriculture are soluble and will rapidly dissolve in water. Once fertilizer $\mathrm{P}$ is dissolved in surface waters, options for effective removal are limited and prohibitively expensive (Anderson and Ceric, 1992; Brown and Caldwell, 1993; BION Technologies, 1994). Some of the direct consequences of excessive $\mathrm{P}$ concentrations in surface waters are algal blooms, low dissolved oxygen levels, excessive aquatic weed growth, increased sedimentation, and greater turbidity (Figure 1a and 1b).

1. This document is SL231, a fact sheet of the Soil and Water Science Department, Florida Cooperative Extension Service, Institute of Food and Agricultural Sciences, University of Florida. Original publication date September 2005. Visit the EDIS Web Site at http://edis.ifas.ufl.edu.

2. O.A. Diaz, T.A. Lang, and M. Chen, Research Associates and S.H. Daroub, Assistant Professor, University of Florida Institute of Food and Agricultural Science, Everglades Research and Education Center, Belle Glade, FL and R.W. Rice Sugarcane Extension Specialist, Palm Beach County, FL.

The Institute of Food and Agricultural Sciences (IFAS) is an Equal Opportunity Institution authorized to provide research, educational information and other services only to individuals and institutions that function with non-discrimination with respect to race, creed, color, religion, age, disability, sex, sexual orientation, marital status, national origin, political opinions or affiliations. U.S. Department of Agriculture, Cooperative Extension Service, University of Florida, IFAS, Florida A. \& M. University Cooperative Extension Program, and Boards of County Commissioners Cooperating. Larry Arrington, Dean 


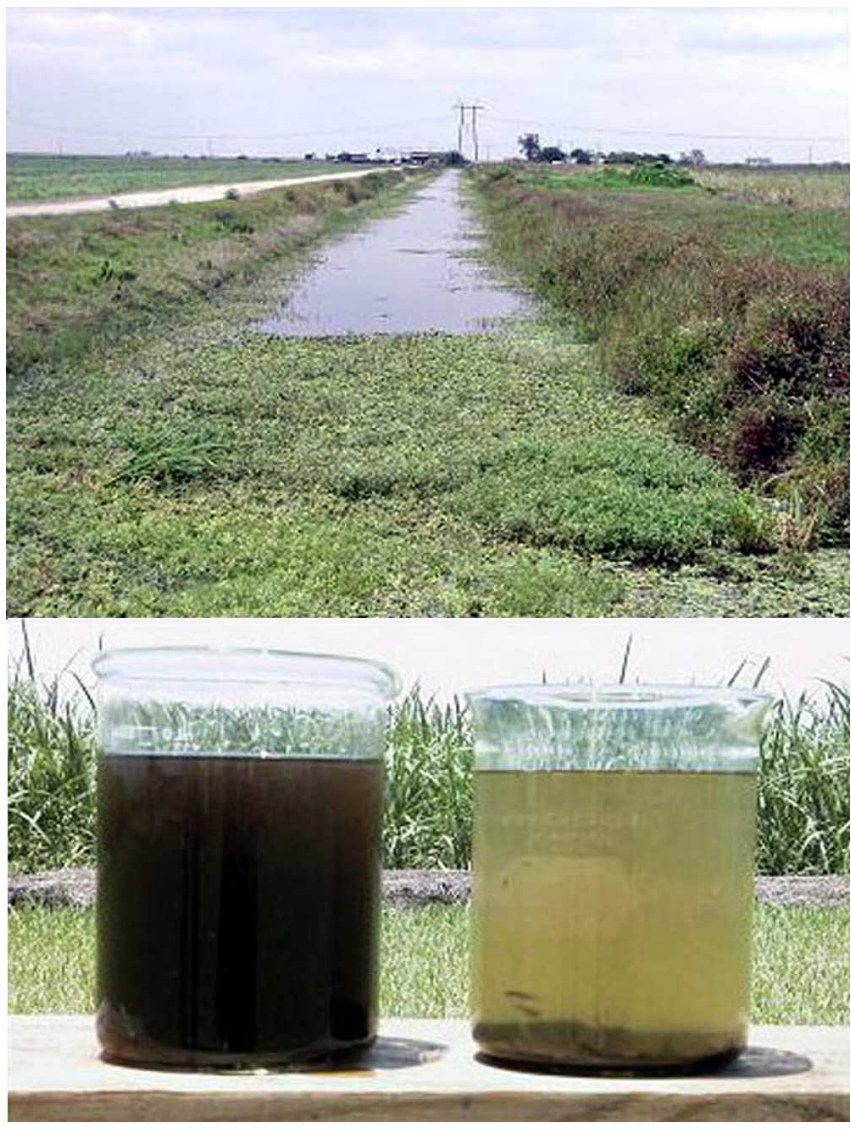

Figure 1. Some effects of high $P$ levels on drainage waters A) proliferation of aquatic vegetation and B) increase in the amount of suspended solids and turbidity.

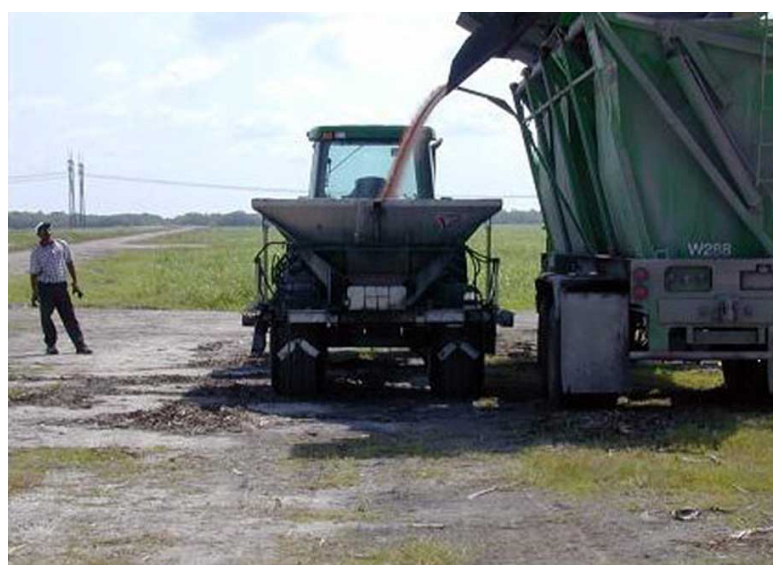

Figure 2. Fertilizer loading site on level ground away from open ditches and canal banks.

Reduced oxygen levels can have harmful effects on fish and other aquatic life, causing reduction in biodiversity and limiting the recreational value of natural resources. Implementing management strategies that maximize P-retention on-farm while also avoiding accidental spills or direct spread of $\mathrm{P}$ fertilizer into open waters will significantly reduce total P loads leaving farms via drainage waters.

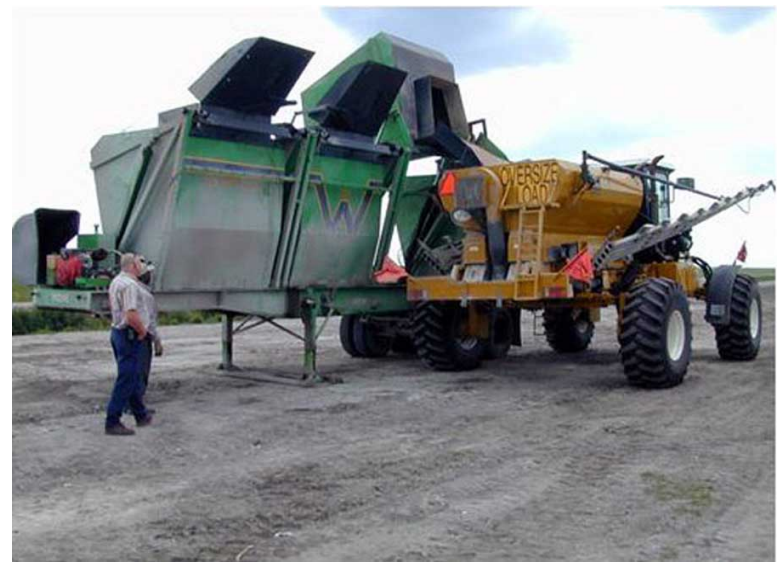

Figure 3. Inspection of a fertilizer loading site.

Some helpful recommendations to reduce the occurrence of fertilizer spills include:

- Park fertilizer hoppers, trailers, and field application rigs far away from field ditches and farm canal banks.

- Park fertilizer hoppers and trailers on level ground (avoid slopes leading to open water; Figure 2).

- Limit the number of fertilizer transfer/loading sites within any given farm in order to facilitate efforts to inspect/police them for unreported spills (Figure 3).

- Fertilizer solution tanks should be rinsed in the field, with the wash water applied to the crops. Tanks should never be rinsed directly or directly emptied into streams, canals, other water bodies, or on roadways.

- Properly train and document all personnel involved in handling fertilizer material.

- As a policy, park fertilizer equipment ONLY on sugarcane loading ramp sites, since these areas are large, flat, and frequently visited.

In the event that a fertilizer spill does occur, the following steps should be taken:

- Contain spills on tarps placed under loading trailers and application rigs receiving the fertilizer.

- Have buckets and shovels available for immediate clean-up. 
- Sweep "mini-spills" off trailers and hoppers onto the tarp and distribute this material within the intended target field.

- As a policy, all personnel involved in handling and spreading fertilizer should have a copy of the Standard Operating Procedures (SOP) that address the procedures for fertilizer spill response.

- The fertilizer spill SOP should identify personnel responsible for cleanup and a chain-of-command for documenting remedial actions taken.

\section{Acknowledgements}

The authors are grateful for the financial support of the Everglades Agricultural Area- Environmental Protection District and The Florida Department of Environmental Protection, funding that enabled the preparation of this document as well as the implementation of the relevant BMP studies described herein.

\section{References}

Anderson, D.L., and A. Ceric. 1992. Reduction of phosphorus concentrations in agricultural drainage of the EAA by precipitation, coagulation, and sedimentation. Technical Report submitted to the Florida Sugar Cane League. University of Florida/IFAS, Everglades Research and Education Center, Belle Glade, FL.

BION Technologies. 1994. Bion Technologies Nutrient Management Systems. Technical Report submitted to the Sugar Cane Growers Cooperative of Florida. BION Technologies, New York.

Brown and Caldwell Consultants. 1993.

Analysis and Development of Chemical Treatment Processes. Technical Report submitted to the South Florida Water Management District, West Palm Beach, FL.

Sharpley, A.N. 1999. Global issues of phosphorus in terrestrial ecosystems. P. 15-46. In K.R. Reddy et al. (ed.), Phosphorus biogeochemistry in subtropical ecosystems. Lewis Pub., Boca Raton, FL. 